Article

\title{
Tools for Wellbeing-Supportive Design: Features, Characteristics, and Prototypes
}

\author{
Dorian Peters $^{1,2, *(\mathbb{D})}$, Naseem Ahmadpour ${ }^{1(D)}$ and Rafael A. Calvo ${ }^{2}(\mathbb{D})$ \\ 1 Design Lab, Sydney School of Architecture, Design and Planning, University of Sydney, \\ 2006 Sydney, Australia; naseem.ahmadpour@sydney.edu.au \\ 2 Dyson School of Design Engineering, Imperial College London, London SW7 1AL, UK; \\ r.calvo@imperial.ac.uk \\ * Correspondence: d.peters@imperial.ac.uk
}

Received: 7 May 2020; Accepted: 6 July 2020; Published: 10 July 2020

\begin{abstract}
While research on wellbeing within Human-Computer Interaction (HCI) is an active space, a gap between research and practice persists. To tackle this, we sought to identify the practical needs of designers in taking wellbeing research into practice. We report on 15 semi-structured interviews with designers from four continents, yielding insights into design tool use generally and requirements for wellbeing design tools specifically. We then present five resulting design tool concepts, two of which were further developed into prototypes and tested in a workshop with 34 interaction design and HCI professionals. Findings include seven desirable features and three desirable characteristics for wellbeing-supportive design tools, including that these tools should satisfy the need for proof, buy-in, and tangibility. We also provide clarity around the notion of design for wellbeing and why it must be distinguished from design for positive emotions.
\end{abstract}

Keywords: design for wellbeing; wellbeing-supportive design; design tools; toolkit; positive computing; positive technology; responsible design

\section{Introduction}

Given the digital environment's influence on psychological health [1] and the increasing public interest in more "humane" products that respect "digital wellbeing" [2], it is surprising that standard design practice has changed so little in response. For example, commercial digital wellbeing initiatives (i.e., by Google [3], Apple [4], and Microsoft [5]) have been created to address public concern, but these largely focus on changing humans rather than on changing technologies (i.e., changing user behavior rather than software design).

However, a focus on digital wellbeing that places some of the responsibility back on technology design is evident in recent digital ethics initiatives (see [6] for a review). Many of these consider support for wellbeing as critical to ethical technology; see the Institute of Electrical and Electronics Engineers's (IEEE) Ethically Aligned Design: A Vision for Prioritizing Human Wellbeing with Autonomous and Intelligent Systems [7].

In order for human wellbeing to become a priority within practice, we need to incorporate new knowledge and methods for designing in wellbeing-supportive ways. However, making wellbeing research and theory available to practicing designers, in ways that are accessible and sensitive to the realities of their working environments, is not trivial. Even once a rigorous theoretical basis has been identified, there are many questions around the components designers in practice would themselves find valuable and be able to use; and which formats, content, and touchpoints for integration would be most effective. 
Therefore, in order to explore possibilities for wellbeing-supportive design resources from the perspective of practitioners, we conducted semi-structured exploratory interviews with technology designers from a variety of specializations (i.e., interaction design, user research, service design, etc.), and from four different countries (US, UK, China, and Australia). Our intention was to deeply explore ideas from a diverse group that could help inform a set of practical tools for professionals that would facilitate wellbeing-supportive design in practice.

Herein, we briefly overview existing work on wellbeing within HCI, including key programs of research. We also take care to clarify the often-conflated concepts of "design for positive emotion" and "design for wellbeing", and show why a distinction is important. We then present findings from the interview study including a set of desirable features and characteristics for wellbeing design tools, and we translate these into five design tool concepts. Finally, we present findings from a workshop in which prototypes of two of the tool concepts were tested. In the Discussion section we synthesize findings from both studies, providing insights for developers of design tools generally and wellbeing-supportive design tools specifically.

\section{Background}

\subsection{Wellbeing as "Optimal Psychological Functioning"}

First, it is worth noting that many disciplines, from industrial and urban design to architecture, already have active research areas in design for wellbeing. Herein, we focus on: (1) technology interaction design and (2) wellbeing as optimal psychological functioning [8] rather than as physical health, or as positive emotions, per se (e.g., "happiness"). We clarify on the second point below.

Design for pleasure, happiness, and satisfaction is clearly an important aspect of positive digital experiences. However, we feel it is important to distinguish this endeavor from design for wellbeing (i.e., "optimal functioning" [8]), because design for positive emotion, while valuable in its own right, will not necessarily result in wellbeing. Some wellbeing researchers have described this as the difference between "feeling good" and "functioning well", providing evidence that there are individuals who rate highly on scales of positive affect (feeling good) but low on positive functioning, and their mental health is measurably lower as a result [9].

There are a number of reasons that designing to increase positive emotions is inadequate as a strategy for supporting wellbeing. Firstly, negative emotions are important to psychological health [10-12] and designing to increase positive emotions will not always be appropriate $[13,14]$. For example, psychologists note that "under some conditions (e.g., the death of a loved one), a person would be considered to be more fully functioning, and ultimately to have greater wellbeing if they experienced rather than avoided the negative feeling of sadness" ([15], p. 151). Secondly, positive emotions can foster illbeing. For example, one might design to boost excitement or increase desire in the context of a shopping or gambling app and contribute to addiction by doing so.

Because wellbeing involves more than positive emotions and because positive emotions can do other things than simply improve wellbeing, designing to increase positive emotions cannot be the same goal as designing for wellbeing. This suggests that tools for practicing designers intended to help them safeguard against psychological harm and support stable wellbeing should be founded from the psychological theory of wellbeing as optimal functioning. Design for positive emotions will likely remain an important strategy within the safeguards of this context, but not a necessary end goal or ultimate measure of wellbeing-supportive design.

\subsection{Research on Wellbeing in $\mathrm{HCI}$}

Research on how to design technologies in ways that support psychological wellbeing has been steadily increasing over the past decade. This is evidenced by the consistent presence of workshops and papers on the topic in HCI conferences (for just a few examples, see [16-19]). The topic of wellbeing in $\mathrm{HCI}$ has been approached through various theoretical lenses and under various names. 
For example, terms as diverse as "emotional wellbeing", "thriving", "eudaimonic UX", "positive" and "wellcomp" have all been used to represent work with the goal of improving psychological wellbeing through technology design [18,20-25]. The employment of psychology theory is similarly diverse, with researchers drawing on positive psychology [22,25], hedonic psychology [26,27] and self-determination theory $[21,23,28]$.

Some examples of ongoing research programs in the wellbeing-supportive design space include work in "positive design", which looks at ways product design can increase subjective wellbeing [25,29]; "positive computing", which focuses on wellbeing-supportive digital technologies [20,30]; "positive technology", which has contributed, in particular, to therapeutic and positive psychology interventions [22,31]; and work in experience design incorporating models of happiness and wellbeing [32-34]. The boundaries are not rigid [35], nor do they need to be, as work in this area is multifaceted and exploratory.

However, for the purposes of this discussion, we are most interested in methods for bridging and practice, which have emerged from HCI work on wellbeing. To our knowledge, only two methods have been proposed: (1) a six-step process by Klapperich et al. [36] and (2) the model for motivation, engagement, and thriving in user experience (METUX) [21].

Klapperich et al. propose the use of social practice theory as a bridge from wellbeing theory into design practice and describe a six-step process centered on understanding positive experiences of daily activities. Social practice theory provides clarity around the elements of routine practices and the approach involves analyzing people who "particularly take joy from a practice", thus providing an alternative to the traditional problem-based approach to design. They describe their contribution in relation to "subjective wellbeing (i.e., happiness)" rather than in relation to wellbeing as optimal functioning per se.

The METUX model relies on Self-Determination Theory (SDT), and therefore takes wellbeing as optimal functioning. It has been described as "the most comprehensive framework for evaluating digital wellbeing to date" [37]), and takes steps to bridge theory and practice by linking a framework of digital experience to a series of wellbeing measures tailored to the technology context. This linking facilitates the measurement of the impacts of a technology design on wellbeing and the tailoring of design in response.

\subsection{Design Tools for Practice}

An established method for bringing theoretical knowledge into practice is through the use of design tools [38]. By "design tools", we refer to designed artefacts, such as card decks, templates, and canvases, intended to assist in some aspect of the design process (e.g., to stimulate creativity, inform ideation, or structure collaboration-we provide a more complete definition in [38]). These tools are often used to consolidate and externalize knowledge so that it can be explicitly incorporated into the design process. For example, the Playful Experiences Framework (PLEX) cards [39] translate the playful experiences framework into an accessible tool for designers and stakeholders to use as part of game design, while the design with intent toolkit [40] facilitates the application of behavior change theories to design.

As background research for the studies described herein, we conducted a systematic review of design tools, details of which are available in a separate article [38]. Our review revealed 76 ideation tools that support the technology design process. A large number of these tools (36) support creativity and other general aspects of design, while more specific tools exist to target areas such as service design, game design, and design for emotions.

For example, emotion design tools include the positive emotional granularity cards [41], which provide tangible access to research on various positive emotions (i.e., pride, lust, fascination, relief), and the design for happiness deck [42], which combines these positive emotions with a set of human virtues and motivations (i.e., courage, curiosity, material gain, bodily sensations, superiority). The cards provide access to concepts that help explain human emotional psychology for designers. 
Bearing in mind our position on distinguishing design for emotions from design to support wellbeing, we classify the emotional granularity cards and happiness deck as tools for emotional design. This is because they include emotions and motivations that influence human behavior but are not considered determinants of wellbeing (e.g., lust, desire for material gain), and if understood as such by designers could lead to unintended negative impacts. For example, if designers see the desire for material gain as a reliable mediator for increasing wellbeing, they are unlikely to be successful (as psychology research on goal contents has shown [43]). However, as tools for understanding emotions and motivations, the cards are extremely helpful as they reify a large number of influential motivators of human behavior. Framed appropriately, they can support both ideation and reflection in user experience.

With respect to tools for wellbeing, the positive practice canvas [32] provides a single example, and is an interview guide and structured notepad for user research designed to gather instances of enjoyable and meaningful practices, which was inspired by the social practice theory approach mentioned above [36]. To date there are no published design tools based on the METUX framework also mentioned above.

\subsection{The Need for Wellbeing-Focused Tools}

While the HCI research programs described in Section 2.3 provide a starting point for wellbeing-supportive design, tools that bring this theory into real-world practice are still lacking. The positive practice canvas, which contributes to the user research phase, provides an example, but more tools are needed, for example for the design and evaluation phases, if wellbeing-supportive design is to become industry-wide best practice.

\subsection{Grounding Design in Rigourous Evidence-Based Research}

Because designing for wellbeing involves shaping people's experiences in order to avoid inadvertent harm, it is critical that wellbeing tools are grounded in rigorous psychology research, well-established theories of wellbeing, and in such a way that specific claims can be traced back to sources.

Taking digital mental health as a cautionary example, failures of rigor have led to an exploding industry of mental health tools that lack evidence, inclusivity, and effectiveness (and at worst, cause harm) [44]. For the second study described in this paper, we addressed this issue by employing self-determination theory (SDT) as a foundation [8]. While there are many wellbeing theories that can inform design, we found that SDT's three basic psychological needs are particularly well-suited for a number of reasons. These reasons are described elsewhere [21,45] but in summary they show that SDTs basic psychological needs:

- Have the strongest available evidence base (over 30 years of psychology research) (see [8] for a review);

- Cannot be overdone, and therefore are safe targets for design [21] (this cannot be said of other proposed needs, such as "stimulation" [34]);

- $\quad$ Are measurable by well-validated psychological instruments [21];

- Function across cultures and developmental stages $[46,47]$.

SDT considers positive emotions (such as happiness) as "signs" or "outcomes" of optimal functioning, rather than mediators, and that one experiences positive emotions when one's fundamental needs are being met. The METUX model described previously applies SDT to technology design and acknowledges that psychological needs can be simultaneously fulfilled (or thwarted) within six spheres of technology experience. These needs and the experience framework form the foundation for the tools described later in this paper. 


\section{Study 1-Interviews with Practitioners}

Study 1 involved interviews with designers to explore opportunities for creating wellbeing-supportive design tools, followed by the design of five tool concepts based on findings.

\subsection{Method}

In order to explore the concepts that practicing designers would find relevant, useful, and appealing with regard to tools that would help them design for wellbeing, we conducted semistructured interviews (6 conducted via video conferencing) with design professionals (i.e., individuals who self-identify as "designers" and who work in an area of technology design). The main research questions were:

1. To what extent do practicing designers use design tools (if at all)?

2. If they do use design tools, how do they use them?

3. Would there be interest among practicing designers in tools for wellbeing-supportive design?

4. What sorts of features and characteristics would make such tools valuable to designers?

The average interview duration was $31 \mathrm{~min}$ (durations ranged from $20 \mathrm{~min}$ to $1.5 \mathrm{~h}$ ).

Participants were asked about their job title, the type of work involved in their role, and previous experience using design tools to help support the design process. To aid understanding of the notion of a "design tool", specific examples were given, including "ideation cards" and "templates".

Participants were then asked about wellbeing-supportive design tools. First, they were asked if they thought there would be interest in such tools within their working environments, and then each participant was asked "what would you want a wellbeing-supportive design toolkit to include?" and "what would make it most helpful for you and your team?"

Designers were recruited through the authors' existing professional and social media networks, with attention paid to representation of various design subfields and geographical regions. This diversity was sought to increase the likelihood of encountering varied experiences and needs, while lending any overlaps a greater likelihood of generalizability across fields and regions. Designers were invited to participate via email. The study was approved by the University of Sydney human research ethics committee, project number 2018/531.

Participants included 15 professional designers, 4 of whom were researchers at a university ( 2 of these also taught design), while the majority (11) worked freelance, worked for a design agency, or worked for a technology company. Participants self-identified in a diverse range of technology-based design roles, including interaction design, service design, learning design, UX, digital art, design management, design research, and experience design. Participants included new and veteran designers with 2-10 years of experience.

Interviews were audio-recorded and transcribed by D.P., and the analyzed by D.P. and N.A. A thematic analysis was conducted based on the phases described by Braun and Clarke [48]. This involved a deductive process of open coding considering both latent and manifest content. First, an initial coding scheme of five top level themes was developed based on the research questions ("previous experience", "purpose of tool use", "interest in wellbeing tools", "desirable characteristics", and "desirable features") for wellbeing-supportive design tools. During coding, an additional top-level theme was identified, "key barriers to designing for wellbeing", owing to a prevalent pattern of emergence across participants in the data. Next, the statements relevant to each theme were analyzed and assigned to subthemes to examine patterns among participant statements. For instance, "delegated authority" and "keeping the peace" were two subthemes of "purpose of tool use". Coding and theme development were conducted using NVivo (v11 for Mac). The process was iterative and "complete" when no more changes were made. 


\subsection{Findings}

\subsubsection{Designers Show Varied Use of Design Tools: From Never to Every Day}

Tool experience varied on a spectrum from no experience with design tools (aside from general-use tools such as sticky notes) $(n=3)$ to designers who were familiar with a wide range of tools and used them frequently $(n=4)$, with most participants falling in between $(n=8)$. For example, one regular tool user (an interaction designer with 6 years of experience) explained:

I have this arsenal (of tools)... endless types of things that I can pick and choose and mix and match to make sure that they really reflect a specific need I have in the project. P13

In contrast, a UX designer with 5 years of experience commented:

You know, to be perfectly honest, I always feel like I want to use them, and then I don't. P12

The most common types of tools used were card decks and canvases. Examples of specific tools participants reported using included Service Design Toolkit [49], Tarot Cards of Tech [50], IDEO Human-Centered Design Toolkit [51], Zig Zag Creativity Card Deck [52], and the Dilemma Co-Exploration Toolkit [53].

\subsubsection{Design Tools Serve Many Different Purposes in Practice}

Participants offered various rationales for using tools in design. These included:

Structuring and focusing activity (e.g., keeping collaborators on track by providing visual structure and focal points);

We might use those in workshops, to structure the conversation or the activity. P10

You have cut that time to productive discussion, you also then focus things. P7

Externalizing concepts (e.g., providing tangible representations of abstract concepts, allowing them to be moved around, structured, and kept in mind);

It is about externalizing ideas in a way that other people can understand them outside of your head. P12

Doing things with physicality and things with paper is really helpful for me because it is nice seeing things in space, which I think is really important. P3

Eliciting thoughts (e.g., triggering ideas);

They are really good at just eliciting thoughts. P13

Democratizing participation (e.g., giving quieter voices alternative methods of communication);

To make sure that the people who are quiet in meetings still have their opinions and their voices heard. P5

I just start watching the quiet people, they will find (their card) and they will just keep putting it back on the table. And then someone will throw it away and then they will just say "No, but this really matters" and if it was a word that they said, they would not be able to keep putting it back into those conversations. P7

Keeping the peace (e.g., providing an agreed process to avoid arguments on what to do next): 
It is a really good way to keep the peace... conflict resolution is key and sometimes having a canvas can be like "This is what we are doing because I said so, otherwise we are just going to get nowhere". P14

Delegating authority (e.g., presenting knowledge or theory in a tool-based form for credibility)

Putting it in a card and selecting it, there is absolutely delegated authority. P7

3.2.3. Interest in a "Wellbeing-Supportive Design Toolkit" Was Supported and Linked to a Growing Interest in Digital Wellbeing and Ethics within the Industry

All 15 participants believed there would be interest in tools for wellbeing-supportive design and offered the following as evidence for this:

- A growing interest in digital wellbeing among designers and the public;

- General interest among designers in avoiding harm;

- A widespread fondness for design tools generally in the industry;

- A growing broader interest in ethics and ethical design.

Examples of participant comments include:

With the development of technology, people pay more and more attention to the psychological needs of users. Therefore, I think all industries need such toolkits to improve users' wellbeing. P15

Well, lately in all the scandals that are coming out, I've seen a massive shift toward ethical design and incorporating -well-there's a huge demand. Like huge, huge, huge demand for integrating wellness and wellbeing into design in every facet that I have worked in. P6

3.2.4. Valuable Characteristics for Wellbeing-Supportive Design Tools include Affordability, Flexibility, and Tangibility

Participants provided varied suggestions as to what characteristics wellbeing-supportive design tools should have. The three characteristics most commonly expressed were affordability, flexibility, and tangibility.

Affordability was a concern for at least 5 of 15 participants who independently stated that the tool would need to be either free or very affordable, or described tools they had opted not to use based on price. Two designers who teach at a university pointed out that tools need to be affordable or offer free versions (such as PDF printouts) if they are to be used by students.

I would have found it more useful to have a really cheap and nasty deck, but physical you know what I mean? So it does not matter if it gets a bit worn. You can hand out ten of them to whoever. P2

I do not want to have to pay for it, because a lot of these toolkits, first of all, the biggest barrier is if you're not working with a company-you're just doing it on your own-then you want it to be free. P8

Flexibility was highlighted by 8 of 15 participants who either described the customization and re-appropriation of tools, or claimed a tool should provide designers with choice about how to use it.

I find with the kits it is very like "you have to do it this way" ... it's like "here's step 1, here's step 2, here's step 3" and that kind of doesn't work for everybody, so having something that's more flexible might be more helpful. P3

Just as a general principle, if it's something that could be adapted and appropriated for many uses then that would be super helpful. As a designer, it might be something I would want to use in other contexts as well. P9 
Tangibility was valued by all participants who expressed this, either by citing specific physical tools they valued (such as cards or whiteboards), or by expressing a preference for materiality more explicitly. For example:

I like the idea of using more cards and more tangible things. P9

They do it, like, on the computer and it's just not the same as moving around in space... Doing things with physicality and things with paper is really helpful for me because it's nice seeing things in space, which I think is really important. P3

A learning designer shared rich personal experiences to demonstrate the benefits of the tangibility of physical card decks, which included "not fixing on a solution too early" because it "feels good" to start over and try something new:

This is theoretically informed conceptual structure in a form to play with, and you don't get fixed ideas too soon ... this is like "OK, we need one more idea from this pile"—and they're taking pictures all the time- "OK, we'll take a record of this and then we'll break it and start again". Whereas if you were doing this in a software package ... you'd fix quicker than this way. So, this way there's no resistance to starting again. It feels good. And the next thing I love is when they start making their own cards. So, they'll start sticking masking tape over them ... or they'll write on them, or they'll tear them in half. I've seen them hidden in back pockets. They sit on them-put them on the floor. People become quite animated and that's nothing to do with me, it's to do with the cards. P7

3.2.5. Valuable Features for Wellbeing-Supportive Design Tools include Evidence, Measures, Strategies, Heuristics, Methods, and Support for Reflection and Client Buy-In

Below is a summary based on our analysis of desirable features for a wellbeing-supportive design tool as expressed by participants (with examples of participant comments verbatim):

Evidence and theory (i.e., psychology and research knowledge to upskill designers and justify design guidance):

More awareness around actually, theory. Designers are like "quality of life this" and "happiness that", but they have no idea about the psychological foundations. They have no idea about - and I am speaking because I have no idea about the deep psychological background behind wellbeing. P2

It might be almost a kind of snapshot of the evidence of why you might do this. P10

The option to read on about the psychology behind something like that. P5

Tests and measures (e.g., for assessing wellbeing-support and evaluating improvements):

I love test-driven development. So, I suppose at the end, maybe not an assessment tool, but a suite of tests to know if you've passed. P6

Maybe make it one of the metrics in addition to usability... What is the impact psychologically? P14

Strategies (i.e., design strategies for wellbeing-support):

So in the same way that you have got these method things, you almost need a pile of strategies that support positive human interaction. P7

Some concise like, you know, "do this" don't do this" kind of thing. P5

Support for understanding and reflection (e.g., case studies or empathy tools for better understanding, and reflecting on, wellbeing impacts of technology): 
I would like something that could help me understand better the ways that digital applications can impact wellbeing. P5

This thing has real world consequences that are really hard to imagine. From the top of my head, it's "what are the different ways to see the world, that I don't see", so like helping to put myself in the place of another. Another thing that I think is quite interesting is like, what are the intended or unintended consequences of the design choices that you have. And I think the real power of these tools is that... they can be used as a generative starting point. P13

Process and methods (e.g., for conducting wellbeing-supportive design):

I hope this toolkit is a series of validated methods that can guide the design of wellbeing at different design stages (such as brainstorming, prototype design, actual design, verification, etc.) P15

Where in the (process) should I be thinking about positive wellbeing, and how I design either the structuring, the layout, or the learning of the course? P7

Heuristics (i.e., rules of thumb for evaluating designs):

Like, Nielsen's heuristics, there is 10 of them. It's quite easy to go, "did that, did that, did that, good". So that would be really helpful but from that wellbeing space. P6

Support for client buy-in (e.g., help convincing decision-makers that wellbeing is worth the investment of resources):

So using, almost, behavioral economics to get stakeholders in the team to consider these things through conversation. That definitely, hands-down, would be the most initially practical and useful tool. P10

\subsubsection{A Key Barrier to Designing for Wellbeing Is Convincing the Client It Is Worth It}

Despite a consensus regarding interest, 8 of the 15 participants voiced concerns over obstacles to achieving wellbeing-supportive design that revolved around misalignment between designers' values and organizational values. Participants expressed concern over difficulty convincing clients and project leaders to invest the extra time and cost that might be required for adding wellbeing into the design process. One user experience designer explained:

Many times, it depends on what the top-level people think, whether it's valuable to do that or not. It's not my decision, even though I try to bring it in, and if the top-level thinks that's wasting time, or they don't see the value of doing that-a lot of times it just disappears. P1

A user experience researcher felt this was the biggest barrier facing designers in relation to wellbeing:

There are common responses, like, quite literally "that's not our problem", "that's not our department's remit"... so a lot of the things that would fall into the category of psychological wellbeing are not considered the remit of the project or the project team. So, the first initial thing-whatever the broader objective is around psychological wellbeing - the first barrier for me has always been around having those conversations. P10

\subsection{Design Concepts Generated from Interview Insights}

As an exercise in translating the results of the qualitative study into actionable design insights, a series of design concepts for practice tools were generated by the authors, each of which responds to the specific needs uncovered in the interview study in different ways. These are presented in Table 1 , along with the features they respond to (based on the feature list above). 
Table 1. Design concepts for practice tools addressing the features desired by designers in study 1 .

\begin{tabular}{|c|c|c|}
\hline Design Concept & Description & Desired Features \\
\hline $\begin{array}{l}\text { Wellbeing Design } \\
\text { Cards }\end{array}$ & $\begin{array}{l}\text { A deck of wellbeing design cards would bring together } \\
\text { several desired features into one accessible and tangible } \\
\text { resource suitable for facilitating ideation, discussion, } \\
\text { critique, and planning. A complete deck might include } 3 \\
\text { "suits" for "evidence and theory", "design strategies", and } \\
\text { "support for reflection" (e.g., reflective prompts) in response } \\
\text { to designer requests for each of these. Content should be } \\
\text { grounded in rigorous psychology research on the } \\
\text { fundamentals of wellbeing and should cite the psychology } \\
\text { research it is based on to meet the need for "evidence and } \\
\text { theory". In addition to supporting design, the cards could } \\
\text { also be used for communication with the client. }\end{array}$ & $\begin{array}{l}\text { Evidence and theory; } \\
\text { strategies; support for } \\
\text { understanding and } \\
\text { reflection; support for } \\
\text { client buy-in }\end{array}$ \\
\hline Client Buy-In Toolkit & $\begin{array}{l}\text { A customizable presentation and conversation scaffold, } \\
\text { which would contain a set of slides with case studies that } \\
\text { demonstrate the risks of ignoring wellbeing issues } \\
\text { (i.e., newspaper articles of technologies that caused harm } \\
\text { and scandal), as well as examples of the benefits of } \\
\text { wellbeing-supportive design to user engagement and trust. } \\
\text { Taking inspiration from previous work on client buy-in for } \\
\text { privacy [54], the conversation scaffold could draw on the } \\
\text { model of non-violent communication. }\end{array}$ & $\begin{array}{l}\text { Support for } \\
\text { understanding and } \\
\text { reflection; support for } \\
\text { client buy-in }\end{array}$ \\
\hline $\begin{array}{l}\text { Wellbeing Impact } \\
\text { Evaluation Kit }\end{array}$ & $\begin{array}{l}\text { This kit would contain a checklist of fundamental heuristics } \\
\text { for evaluating existing designs and a set of validated } \\
\text { psychology questionnaires to allow for designers to quantify } \\
\text { psychological wellbeing before and after design changes to } \\
\text { a technology. }\end{array}$ & $\begin{array}{l}\text { Tests and measures; } \\
\text { heuristics }\end{array}$ \\
\hline $\begin{array}{l}\text { The Wellbeing Taster } \\
\text { Workshop }\end{array}$ & $\begin{array}{l}\text { A set of activities (making use of the other tools) to introduce } \\
\text { teams to the core concepts and methods of } \\
\text { wellbeing-supportive design in half a day. The workshop } \\
\text { could combine many of the requested features within an } \\
\text { interactive professional development format that also } \\
\text { modeled use of the other tools. }\end{array}$ & $\begin{array}{l}\text { Evidence and theory; } \\
\text { support for } \\
\text { understanding and } \\
\text { reflection; process } \\
\text { and methods }\end{array}$ \\
\hline $\begin{array}{l}\text { The Wellbeing } \\
\text { Design Sprint }\end{array}$ & $\begin{array}{l}\text { An orchestration guide for } 5 \text { days of activities, in which } \\
\text { mixed teams are introduced to the core concepts of } \\
\text { wellbeing-supportive design (elements of the taster } \\
\text { workshop) and then given opportunities to apply these to } \\
\text { their own projects. The team would also collaboratively } \\
\text { generate ideas for new products or product redesign ideas } \\
\text { based on improving support for wellbeing. The outcomes } \\
\text { would include professional development, team building, } \\
\text { and product innovation. }\end{array}$ & $\begin{array}{l}\text { Evidence and theory; } \\
\text { strategies; support } \\
\text { for understanding } \\
\text { and reflection; } \\
\text { process and methods; } \\
\text { heuristics; support } \\
\text { for client buy-in }\end{array}$ \\
\hline
\end{tabular}

\section{Study 2-Prototyping Workshop}

\subsection{Materials}

Of the high-level design concepts described above, two were selected for further development and prototype testing - the "wellbeing taster workshop" and "wellbeing design cards". These were selected based on the criteria that they provide the greatest coverage of desired features, while still allowing sufficient flexibility for broad use. For example, while the sprint would cover more features, it requires a 5-day commitment from a team within an organization. The taster workshop and cards, in contrast, provide nearly as much coverage of features but with more flexible, lower-commitment requirements. We describe the resulting prototypes below, followed by the method for and findings from testing these two prototypes. 


\subsubsection{Wellbeing Taster Workshop}

The wellbeing taster workshop was designed to introduce designers to fundamental psychology theory and concepts that inform wellbeing-supportive design, and to provide participants with the opportunity to apply these concepts in a design context. The workshop is designed to be run over $2.5 \mathrm{~h}$. The first hour includes a presentation summarizing the psychological and HCI theory underpinning the workshop activities and goals. The second half consists of two group activities followed by a closing group discussion. The first activity engages participants in analyzing a technology scenario through the lens of the theory provided during the first half. The second activity calls on groups to redesign an existing technology in order to improve support for wellbeing. The METUX model [21] was provided as the framework for analysis.

Figure 1 shows examples of materials developed for the workshop: (a) a persona and technology description to communicate the context and (b) a template for collecting ideas in relation to the given scenario.

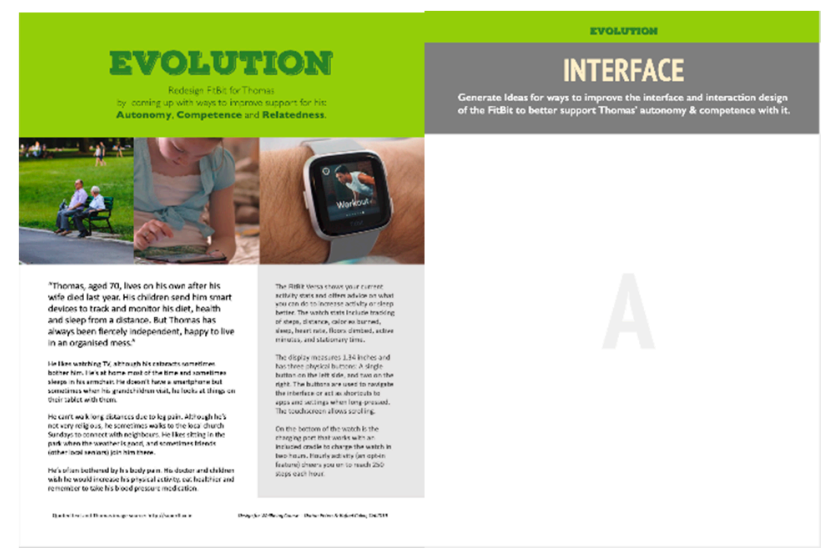

Figure 1. Example materials developed for the prototype workshop. To the (left) is a persona and technology overview and to the (right) is a blank template for ideas.

\subsubsection{Wellbeing Design Cards}

The wellbeing design cards deck was created to provide a reference point for theory and evidence in a concise and tangible format. Specifically, we designed the cards to incorporate the three determinants of wellbeing identified as "basic psychological needs" (autonomy, competence, and relatedness) [8] and the six spheres of technology experience (adoption, interface, task, behavior, life, society) [21] used by the METUX model [21] in order to provide users of the cards with various frames of analysis. While a final version of the cards would have additional categories ("suits"), our goal for this initial prototype was to start with the "evidence and theory" category and provide a reference tool for the taster workshop. Example cards are shown in Figure 2 and the set is downloadable at http://www.positivecomputing.org/p/projects.html.

\subsection{Method}

An initial version of the "wellbeing taster workshop and wellbeing design cards" was tested as part of a professional development course at the conference on Human Factors and Computing Systems (CHI) in 2019, facilitated by D.P. and R.C. and advertised via the conference website [17]. Participants of the course were invited to take part in the study by completing an evaluation questionnaire at the end of the workshop. The questionnaire was developed by the researchers to capture participants' feedback and consisted of 3 closed questions on participant job role (e.g., researcher, practitioner, student), field (e.g., HCI, UX, engineering, psychology, health, ethics), and previous experience with methods for designing for wellbeing. These were then followed by 10 questions in which participants rated their 
views of the design activities they engaged in (on 5-point scales, ranging from strongly disagree to strongly agree). These included rating the activity against attributes such as "valuable", "engaging", "useful", rating the wellbeing design cards on the extent they were useful, enjoyable, unnecessary, or difficult to use, as well as rating interest (likelihood of future use, recommendation to others, and satisfaction). Finally, participants responded to 5 open-ended questions seeking feedback on the value of both the content and format of the workshop and tools, including components that worked well and that could be improved.

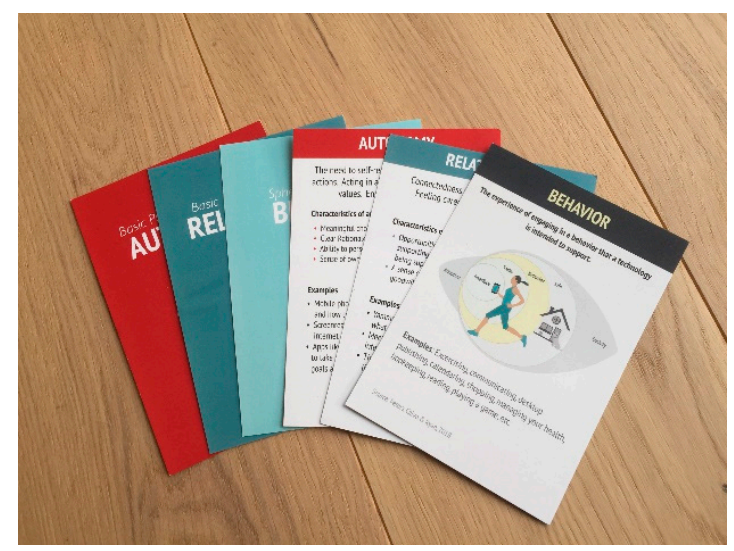

Figure 2. Cards from the "wellbeing design cards" deck.

Recruiting participants via an HCI-based conference provided face-to-face access to a large international group of professionals and allowed feedback to be gathered, not only from practicing designers, but also design researchers and future designers (students). There was no overlap between participants in the interview study (many of whom were interviewed remotely via video conferencing software) and the participants at the face-to-face workshop.

The workshop was conducted with 42 participants (34 of whom responded to the study questionnaire). According to the survey, 25 of 34 (75\%) participants identified with the field of $\mathrm{HCI}$, while $22(65 \%)$ more specifically identified with "user experience, user interface design, or interaction design." Fourteen (41\%) were from the fields of "health, psychology, or mental health", with some overlap across fields. Participants also identified as practitioners ( 9 participants, $26 \%$ ), researchers (18 participants, 53\%), or students (17 participants, 50\%). Observations and preliminary quantitative results from the questionnaire are summarized below.

\subsection{Findings}

A majority of the participants (28 participants, $82 \%$ ) agreed or strongly agreed with the statement, "I am likely to use what I learned today in my practice", indicating support for the value of wellbeing design knowledge for practice.

A slight majority of the participants (19 participants, 56\%) agreed that "the wellbeing design activity was a useful learning experience", while about one-third were neutral or left the field blank $(\mathrm{n}=12,35 \%)$ and $2(6 \%)$ disagreed that the activity was useful. Many participants offered written explanations about the need for more instruction and more time for activities (quotations are labelled by questionnaire number):

More detailed instructions, more time. Q16

More time, improve briefing. Q1

Tell us a bit more of the task. Q4

More time, clearer instructions. Q8 
The same number of participants $(\mathrm{n}=19,56 \%)$ agreed or strongly agreed that "the wellbeing tools (cards and materials) were useful for the activity", with some adding specific rationale for this appraisal:

Liked the materials for the activity. Very engaging and well crafted. Q18

Refs (research references) are useful and nice clear concepts. Q19

The cards/concepts will help me ground arguments I make in research and wider practice. Q22

Good reference point_-clear, concise reference to each determinant. Q26

However, a substantial minority were neutral or disagreed that the materials contributed to the workshop, while some explained that they were not used by their group:

Did not know how to use them or have time to use them. Q17

A hint that we should use the cards would have been very useful (I did not). More time to read the instruction would be helpful as well. Q34

Didn't use them. Not enough time. Q29

We kind of forgot about using them. Q25

In summary, $56 \%$ of respondents agreed or strongly agreed that both the workshop and tools were useful, while $82 \%$ found the overall topic and content valuable for their work. However, the remainder were neutral or dissatisfied with the activities and tools. Responses to open-ended questions highlighted insufficient time for the activities and insufficient instruction on how to incorporate the tools into the activities.

\section{Discussion}

Interviews with 15 professional designers revealed a set of 7 desirable features and 3 desirable characteristics for tools to facilitate wellbeing-supportive design, and that designers valued the topic for their work. Interview findings led to the development of a prototype "wellbeing taster workshop and wellbeing design cards" deck, which were then assessed via questionnaire with 34 attendees at an $\mathrm{HCI}$ conference. Findings from the questionnaire provide further support for the view that wellbeing design knowledge is relevant to practice ( $82 \%$ said they were likely to use what they had learned in their work) and revealed a number of areas for improvement to the prototype workshop and card deck. Below, we discuss reflections on these results, including: (1) the need for proof, (2) the need for buy-in, and (3) the need for tangibility, as well as (4) the need for clear instruction and sufficient time (including suggestions for improving the prototypes tested in response to the workshop study).

\subsection{The Need for Proof}

Theory and evidence were seen as both necessary for legitimacy and important knowledge for improving practice by interviewees. Workshop participants corroborated this valuing of theory and evidence in open-ended comments. Bringing wellbeing into design practice in a rigorous way will require that designers increase their knowledge of wellbeing psychology. Tools that make this process easier and that allow learning to be seamlessly integrated into practice can facilitate this leap. We responded to the need for proof by prototyping a "wellbeing taster workshop" concept and "wellbeing design cards", both of which consolidated and presented evidence-based knowledge and theory within the context of application. 


\subsection{The Need for Buy-In}

While design tools are typically those that support phases of the design process itself, it is important to acknowledge that the need to make the case to others (especially funders and decision-makers) about the value of wellbeing-supportive design was expressed strongly by a majority of interviewees and was described by one as a need for "tools for conversations". The same participant suggested that any tool for buy-in should highlight the risks of not designing for wellbeing, since perceived risks may be more persuasive than perceived benefits. This aligns with related work on privacy-friendly design, in which Muller and Lévy [54] demonstrate the role that design fictions can play in educating and convincing the client. In leading conversations about the importance of designing for wellbeing, designers can be seen as taking on the role of advocate for a shift in values within the technology industry. This is similar to the way advocates for accessibility have worked to educate clients in the importance and longer term benefits of investing in inclusive design. While we were not able to prototype a client buy-in tool for this study, work on such a tool would clearly form an important and valued contribution.

\subsection{The Need for Tangibility}

It is worthy of note that all the examples of tools cited by participants were material (rather than digital). These included general tools such as sticky notes and white boards, but also purpose-built tools (such as commercially available card decks and kits), customizable tools (such as canvases), and bespoke tools (created for specific projects). Interviewees were also explicit about favoring physical tools and described unique benefits. This appreciation for the benefits of tangibility should not be surprising, as research has demonstrated that analogue tools dominate the early stages of design $[55,56]$. Yeoman and Carvalho [57] describe some of the benefits of tangibility in their description of successful design synthesis:

Successful collaborations of this nature depend on the materialization and subsequent spatial orientation of information and ideas relevant to the task, and an ability to communicate and work with others to identify potential design solutions and converge on a single 'good' as opposed to a "correct" solution. (p. 85)

They also highlight the utility of gestures to shared sense-making and the value of external tools in the productive management of microconflicts and in supporting the negotiation of consensus-all points echoed by various participants in our interview study with respect to their reasons for using tools. Because of this finding, we suggest wellbeing design tools, where possible, consider material experience.

However, following study 2, the 2020 COVID-19 pandemic and associated lockdown highlighted the importance of alternatives to face-to-face practice. Interesting research questions for future investigation emerge: To what extent is the preference for materiality simply a result of familiarity and prior experience? (We are more experienced at leveraging the advantages of tangible interaction for collaborative design.) To what extent could alternative methods to achieving the same benefits or even new and unique benefits be found through the creative use of virtual collaborative technologies? How might smart objects be used to bridge the boundary between tangible and virtually connected spaces? Research into such questions would benefit not only design tool development, but also the practice of design and collaboration more broadly in a world likely to rely more heavily on virtual interaction in future.

\subsection{The Need for Rigor}

In addition to the user needs summarized above, we propose the need for rigor (as elaborated in the introduction). Our studies suggest that designers value theory and evidence, but it is up to the makers of design tools to ensure that the theory and evidence provided are rigorous by academic standards. Because designing for wellbeing involves shaping experience, it is critical that efforts are grounded in well-established and evidence-based psychological theories of wellbeing. We have 
additionally clarified that these should be theories of wellbeing as "optimal functioning" rather than relying on research on "positive emotions", which are an important part of-but not equivalent by themselves-to wellbeing. Within our study, we employed self-determination theory as an option that meets these and other important criteria (strong research evidence, a focus on optimal functioning, safe design targets, and applicability to technology contexts). We encourage future research to evaluate possible alternative theories that similarly embody these criteria. What is essential is that any theoretical foundation is thoroughly backed by peer-reviewed research and evaluation.

\subsection{The Need for Clear Instruction and Sufficient Time-Interpreting Workshop Results}

Results of the workshop evaluation questionnaire indicate that the theme and content of the workshop were valued as relevant to practice, but that problems with the orchestration of the event provided ample room for improvement in future iterations. A contributing factor to orchestration weaknesses resulted from the workshop venue being changed within $10 \mathrm{~min}$ of the start time, which caused a delayed start, and a consequent rush to keep to the schedule. In the rush, facilitators neglected to explain the purpose of the cards within the activity. As such, many participants did not know how the cards might be useful to the activities and supplied open-text responses requesting "more time" and "more instruction".

The responses suggest that there were two very different experiences had by participants, as demonstrated by two response clusters. Scores were consistently positive for just over half of participants who agreed that neither the activities nor the cards were useful. The second cluster was consistent across question responses in feeling either neutral or that the activities and cards were not useful. It is difficult to determine a cause for the dramatic difference between the two groups. There was no correlation between positive experience and a participant's role, field, or previous experience. It is, therefore, possible that experiences were clustered by physical grouping. During the workshop, participants sat themselves around tables with approximately 8 people at each, and it is possible that those with consistently positive feedback participated in groups that for some circumstantial reason (e.g., the mix of experience levels in the group) were able to overcome the weaknesses of the orchestration. Of course, this is speculative; however, the fact that a majority of participants had a positive experience despite circumstantial weaknesses suggests that resolution of these obstacles in future workshops could yield substantially better results.

In summary, the results demonstrate the potential for the workshop to provide value to participants; providing a redesign of activities and tighter orchestration are included for future iterations in order to ensure effective group collaboration and clarity around the use of tools. This also suggests the importance of clear instruction more generally as part of tool design.

\subsection{Limitations}

There are important limitations to this research with regard to sampling. Firstly, the interviews explored the experiences of 15 designers of diverse backgrounds. This qualitative approach provided details into preferences; however, the extent to which these preferences are generalizable across the professional design population would need to be determined by future studies with larger cohorts. To some extent, the generalizability of the insights emerging from interviews was tested in study 2; however, the participant sample of study 2 contained more researchers and fewer industry professionals, which could bias the results. As such, future studies with larger numbers of professional designers will help to determine the applicability of the findings.

\subsection{Future Work}

Our future work will involve improving existing prototypes and developing additional design concepts presented herein. We hope to carry out an iterative process of testing and improvement, which will include evaluation with larger numbers and with both novice and experienced designers in both academic and commercial settings using validated evaluation tools. 
In addition, since the initial drafting of this paper, the onset of the 2020 COVID-19 lockdown and ensuing restrictions on face-to-face interaction caused us to reconsider how we proceed with future work in this area. As a result, we have decided to test a remote version of the workshop and are experimenting with various ways to retain some tangibility within the virtual context and work with "virtual tangibility" via collaborative ideation software. We hope to contribute to understanding around how the benefits of materiality within face-to-face group interaction can be retained, or compensated for, by alternative benefits unique to online experience.

\section{Conclusions}

In this paper, we have described work intended to respond to a need for bridging theory and practice in wellbeing-supportive design by informing the creation of tools for this purpose. Specifically, we have: (1) reported on a study that identified needs and preferences of practicing designers with respect to wellbeing-supportive design tools, including three characteristics (affordability, flexibility, and tangibility) and seven features (evidence, measures, strategies, methods, heuristics, support for reflection, and support for buy-in); and (2) reported on the design and testing of two tool prototypes that respond to those needs. Prototype testing provided further evidence for the desire for theory and evidence, and for a belief that wellbeing-supportive design knowledge is valuable to design practice. However, the results also revealed significant room for improvement with respect to providing more time and instruction.

We have also summarized evidence for why distinguishing "design for positive emotions" from "design for wellbeing" (as optimal functioning) is critical. Because wellbeing involves more than positive emotions, and as positive emotions can do other things than improve wellbeing, designing to increase positive emotions cannot be the same goal as designing for wellbeing

We hope that the findings herein and the tools presented can help contribute to future tool development, to work in wellbeing-supportive design more generally, and to more ethical design practice overall. Our broader hope is to contribute towards a transformation in the field that makes support for psychological wellbeing a technology design norm.

Author Contributions: Conceptualization, D.P., N.A., and R.A.C.; methodology, D.P., N.A., and R.A.C.; formal analysis, D.P. and N.A.; writing—original draft preparation, D.P.; writing-review and editing, D.P., N.A., and R.A.C.; visualization, D.P.; supervision, N.A. All authors have read and agreed to the published version of the manuscript. Please turn to the CRediT taxonomy for the term explanation. Authorship must be limited to those who have contributed substantially to the work reported.

Funding: This research received no external funding.

Conflicts of Interest: The authors declare no conflict of interest.

\section{References}

1. Attrill, A. (Ed.) Cyberpsychology; Oxford University Press: Oxford, UK, 2015.

2. Center for Humane Technology. Center for Humane Technology. 2019. Available online: https://humanetech.com/ (accessed on 28 January 2020).

3. Digital Wellbeing through Technology. Available online: https://wellbeing.google/ (accessed on 27 January 2020).

4. Solon, O. Apple's New 'Digital Wellbeing' Tools Aim to Help Reduce Screen Time; The Guardian: San Francisco, CA, USA, 2018.

5. Microsoft.com. MyAnalytics Wellbeing Page. 2019. Available online: https://docs.microsoft.com/en-us/ workplace-analytics/myanalytics/use/wellbeing (accessed on 27 January 2020).

6. Floridi, L.; Cowls, J.; Beltrametti, M.; Chatila, R.; Chazerand, P.; Dignum, V.; Luetge, C.; Madelin, R.; Pagallo, U.; Rossi, F.; et al. AI4People-An ethical framework for a good AI society: Opportunities, risks, principles, and recommendations. Minds Mach. 2018, 28, 689-707. [CrossRef] [PubMed] 
7. Chatila, R.; Firth-Butterflied, K.; Havens, J.C.; Karachalios, K. The IEEE global initiative for ethical considerations in artificial intelligence and autonomous systems. IEEE Robot. Autom. Mag. 2017, 24, 110. [CrossRef]

8. Ryan, R.M.; Deci, E.L. Self-Determination Theory: Basic Psychological Needs in Motivation, Development, and Wellness; The Guilford Press: New York, NY, USA, 2017; p. 10.

9. Keyes, C.L.M.; Annas, J. Feeling good and functioning well: Distinctive concepts in ancient philosophy and contemporary science. J. Posit. Psychol. 2009, 4, 197-201. [CrossRef]

10. Kashdan, T.B.; Biswas-Diener, R. The Power of Negative Emotion: How Anger, Guilt, and Self Doubt are Essential to Success and Fulfillment; Oneworld Publications: London, UK, 2015.

11. Tappolet, C.; Teroni, F.; Ziv, A.K. Shadows of the Soul: Philosophical Perspectives on Negative Emotions; Routledge: New York, NY, USA, 2018.

12. Ford, B.Q.; Lam, P.; John, O.P.; Mauss, I.B. The psychological health benefits of accepting negative emotions and thoughts: Laboratory, diary, and longitudinal evidence. J. Pers. Soc. Psychol. 2018, 115, 1075-1092. [CrossRef]

13. Fokkinga, S.F.; Desmet, P.M.A. Ten ways to design for disgust, sadness, and other enjoyments: A design approach to enrich product experiences with negative emotions. Int. J. Des. 2013, 7, 19-36.

14. Brubaker, J.R.; Hayes, G.R.; Mazmanian, M. Orienting to Networked Grief. Proc. Acm Hum. Comput. Interact. 2019, 3, 1-19. [CrossRef]

15. Ryan, R.; Deci, E.L. On Happiness and Human Potentials: A Review of Research on Hedonic and Eudaimonic Well-Being. Annu. Rev. Psychol. 2001, 52, 141-166. [CrossRef]

16. Cecchinato, M.E.; Rooksby, J.; Hiniker, A.; Munson, S.; Lukoff, K.; Ciolfi, L.; Thieme, A.; Harrison, D. Designing for digital wellbeing. In Proceedings of the Extended Abstracts of the $2019 \mathrm{CHI}$ Conference on Human Factors in Computing Systems, Glasgow, UK, 4-9 May 2019; p. W17.

17. Calvo, R.A.; Peters, D. Design for wellbeing-Tools for research, practice and ethics. In Proceedings of the Extended Abstracts of the 2019 CHI Conference on Human Factors in Computing Systems, Glasgow, UK, 4-9 May 2019; p. C15.

18. Okoshi, T.; Ko, J.G.; Pirttikangas, S.; Nakazawa, J.; Kawsar, F. WellComP 2018: First international workshop on computing for well-being. In Proceedings of the UbiComp '18: Proceedings of the 2018 ACM International Joint Conference and 2018 International Symposium on Pervasive and Ubiquitous Computing and Wearable Computers, Tokyo, Japan, 9-11 October 2018; pp. 684-687.

19. Tondello, G.F.; Orji, R.; Vella, K.; Johnson, D.; Van Dooren, M.M.; Nacke, L. Positive gaming. Ext. Abstr. Publ. Annu. Symp. Comput. 2017, 657-660. [CrossRef]

20. Calvo, R.; Peters, D. Positive Computing: Technology for Wellbeing and Human Potential; The MIT Press: Cambridge, UK, 2014.

21. Peters, D.; Calvo, R.A.; Ryan, R. Designing for motivation, engagement and wellbeing in digital experience. Front. Psychol. 2018, 9, 797. [CrossRef]

22. Riva, G.; Baños, R.M.; Arbona, C.B.; Wiederhold, B.K.; Gaggioli, A. Positive technology: Using interactive technologies to promote positive functioning. Cyberpsychol. Behav. Soc. Netw. 2012, 15, 69-77. [CrossRef]

23. Müller, L.J.; Mekler, E.D.; Opwis, K. Facets in HCI: Towards understanding eudaimonic UX-Preliminary findings. In Proceedings of the 33rd Annual ACM Conference Extended Abstracts on Human Factors in Computing Systems, Seoul, Korea, 18 April 2015; Volume 2, pp. 2283-2288.

24. Coyle, D.; Thieme, A.; Linehan, C.; Balaam, M.; Wallace, J.; Lindley, S. Emotional wellbeing. Int. J. Hum. Comput. Stud. 2014, 72, 627-628. [CrossRef]

25. Desmet, P.; Pohlmeyer, A.E. Positive design: An introduction to design for subjective well-being. Int. J. Des. 2013, 7, 5-19.

26. Diefenbach, S.; Kolb, N.; Hassenzahl, M. The 'hedonic' in human-computer interaction. In Proceedings of the 2014 Conference on Genetic and Evolutionary Computation, Vancouver, BC, Canada, 12-16 July 2014; pp. 305-314.

27. Hancock, P.A.; Pepe, A.A.; Murphy, L.L. Hedonomics: The power of positive and pleasurable ergonomics. Erg. Des. Q. Hum. Factors Appl. 2005, 13, 8-14. [CrossRef]

28. Deterding, S. Eudaimonic design, or: Six invitations to rethink gamification. In Rethinking Gamification; Fuchs, M., Fizek, S., Ruffino, P., Schrape, N., Eds.; Meson Press: Lüneburg, Germany, 2014; pp. 305-331. 
29. Pohlmeyer, A.E. How design can (not) support human flourishing. In Positive Psychology Interventions in Practice; Springer Science and Business Media LLC: Cham, Switzerland, 2017; pp. 235-255.

30. Calvo, R.A.; Peters, D. Promoting psychological wellbeing: Loftier goals for new technologies. IEEE Technol. Soc. Mag. 2013, 32, 19-21. [CrossRef]

31. Gaggioli, A.; Villani, D.; Serino, S.; Banos, R.; Botella, C. Editorial: Positive technology: Designing E-experiences for positive change. Front. Psychol. 2019, 10, 1571. [CrossRef]

32. Klapperich, H.; Laschke, M.; Hassenzahl, M. The positive practice canvas. In Proceedings of the 10th Nordic Conference on Human-Computer Interaction, Oslo, Norway, 1-3 October 2018; pp. 74-81. [CrossRef]

33. Hassenzahl, M.; Wiklund-Engblom, A.; Bengs, A.; Hägglund, S.; Diefenbach, S. Experience-oriented and product-oriented evaluation: Psychological need fulfillment, positive affect, and product perception. Int. J. Hum. Comput. Interact. 2015, 31, 530-544. [CrossRef]

34. Hassenzahl, M.; Eckoldt, K.; Diefenbach, S.; Laschke, M.; Lenz, E.; Kim, J. Designing moments of meaning and pleasure. Experience design and happiness. Int. J. Des. 2013, 7, 21-31.

35. Gaggioli, A.; Riva, G.; Peters, D.; Calvo, R.A. Positive technology, computing, and design: Shaping a future in which technology promotes psychological well-being. Emot. Affect Hum. Factors Hum. Comput. Interact. 2017, 477-502. [CrossRef]

36. Klapperich, H.; Laschke, M.; Hassenzahl, M.; Becker, M.; Cürlis, D.; Frackenpohl, T.; Köhler, H.; Ludwigs, K.; Tippkämper, M. Mind the Gap: A social practice approach to wellbeing-driven design. In Design for Wellbeing an Applied Approach; Petermans, A., Cain, R., Eds.; Routledge: London, UK, 2019.

37. Burr, C.; Taddeo, M.; Floridi, L. The ethics of digital well-being: A thematic review. SSRN Electron. J. 2019, 1-35. [CrossRef]

38. Peters, D.; Loke, L.; Ahmadpour, N. Toolkits, cards and games-A review of analogue tools for collaborative ideation. CoDesign 2020. [CrossRef]

39. Lucero, A.; Arrasvuori, J. The PLEX cards and its techniques as sources of inspiration when designing for playfulness. Int. J. Arts Technol. 2013, 6, 22. [CrossRef]

40. Lockton, D. Design with Intent: A design pattern toolkit for environmental \& social behaviour change. Ph.D. Thesis, Brunel University School of Engineering and Design, London, UK, 2013.

41. Yoon, J.; Desmet, P.M.A.; Pohlmeyer, A.E. Embodied typology of positive emotions: The development of a tool to facilitate emotional granularity in design. In Proceedings of the International Congress of International Association of Societies of Design Research, Tokyo, Japan, 26-30 August 2013; pp. 1206-1217.

42. Desmet, P.M.A.; Pohlmeyer, A.E. Design for Happiness Deck; Delft University of Technology: Delft, The Netherlands, 2017.

43. Sheldon, K.M.; Ryan, R.; Deci, E.L.; Kasser, T. The independent effects of goal contents and motives on well-being: It's both what you pursue and why you pursue it. Pers. Soc. Psychol. Bull. 2004, 30, 475-486. [CrossRef] [PubMed]

44. Larsen, M.E.; Huckvale, K.; Nicholas, J.; Torous, J.; Birrell, L.; Li, E.; Reda, B. Using science to sell apps: Evaluation of mental health app store quality claims. npj Digit. Med. 2019, 2, 18. [CrossRef]

45. Calvo, R.A.; Peters, D.; Vold, K.; Ryan, R.M. Supporting human autonomy in AI systems: A framework for ethical enquiry. In Ethics of Digital Wellbeing: A Multidisciplinary Approach; Burr, C., Floridi, L., Eds.; Springer: Berlin, Germany, 2019.

46. Chen, B.; Vansteenkiste, M.; Beyers, W.; Boone, L.; Deci, E.L.; Van Der Kaap-Deeder, J.; Duriez, B.; Lens, W.; Matos, L.; Mouratidis, A.; et al. Basic psychological need satisfaction, need frustration, and need strength across four cultures. Motiv. Emot. 2014, 39, 216-236. [CrossRef]

47. Véronneau, M.; Koestner, R.F.; Abela, J.R. Intrinsic need satisfaction and well-being in children and adolescents: An application of the self-determination theory. J. Soc. Clin. Psychol. 2005, 24, 280-292. [CrossRef]

48. Braun, V.; Clarke, V. Thematic analysis. APA Handb. Res. Methods Psychol. Res. Des. Quant. Qual. Neuropsychol. Biol. 2012, 2, 57-71. [CrossRef]

49. Namahn and Flanders DC. Service Design Toolkit. 2019. Available online: https:/www.servicedesigntoolkit.org/ (accessed on 28 January 2020).

50. Artefact Group. The Tarot Cards of Tech. Available online: http://tarotcardsoftech.artefactgroup.com/ (accessed on 28 January 2020).

51. IDEO.org. Design Kit. Available online: https://www.designkit.org/ (accessed on 28 January 2020). 
52. Sawyer, K.R. Zig Zag Creativity Card Deck. 2015. Available online: http://keithsawyer.com/zzdeck/ (accessed on 28 January 2020).

53. Ozkaramanli, D. Me against Myself-Addressing Personal Dilemmas through Design. Ph.D. Thesis, Delft Institute of Positive Design, Delft, The Netherlands, 2017.

54. Muller, D.A.; Lévy, P. A design approach towards affording the trend of privacy. In Proceedings of the 2019 on Designing Interactive Systems Conference, San Diego, CA, USA, 23-28 June 2019.

55. Borum, N.; Brooks, E.I.; Frimodt-Møller, S.R. The resilience of analog tools in creative work practices: A case study of LEGO future lab's team in billund. In Intelligent Tutoring Systems; Springer Science and Business Media LLC: Cham, Switzerland, 2014; Volume 8510, pp. 23-34.

56. Inie, N.; Dalsgaard, P. How interaction designers use tools to capture, manage, and collaborate on ideas. In Proceedings of the 2017 CHI Conference Extended Abstracts on Human Factors in Computing Systems, Denver, CO, USA, 6-11 May 2017; pp. 2668-2675.

57. Yeoman, P.; Carvalho, L. Moving between material and conceptual structure: Developing a card-based method to support design for learning. Des. Stud. 2019, 64, 64-89. [CrossRef]

(C) 2020 by the authors. Licensee MDPI, Basel, Switzerland. This article is an open access article distributed under the terms and conditions of the Creative Commons Attribution (CC BY) license (http://creativecommons.org/licenses/by/4.0/). 